\title{
The use of Caffeine by people with Epilepsy: the myths and the evidence Prisca R Bauer ${ }^{1}$, Josemir W Sander ${ }^{2,3,4}$
}

1: INSERM U1028 - CNRS UMR5292 -UCBL Centre Hospitalier Le Vinatier (Bât. 462) Neurocampus, 95 Bd Pinel, 69675 Bron cédex, France

2: Stichting Epilepsie Instellingen Nederland (SEIN), Heemstede, The Netherlands

3: NIHR University College London Hospitals Biomedical Research Centre, UCL Queen Square Institute of Neurology, Queen Square, London WC1N 3BG, \& Chalfont Centre for Epilepsy, Chalfont St Peter SL9 0RJ, UK

For submission to

Corresponding author:

Telephone number:

E-mail address:
Ley Sander

+44203448 8612

1.sander@ucl.ac.uk

Number of words in abstract:

Number of words in manuscript body total: 3061

Number of figures: 0

Number of tables: $\quad 0$

\section{Abstract [148/150 words]}

Purpose of review: Caffeine is the most widely consumed central nervous stimulant. For people with epilepsy, it is often unclear whether drinking coffee carries a risk of triggering seizures.

Recent findings: The relationship between caffeine, seizures, epilepsy and anti-seizure drugs is not fully understood. Clinical studies are scarce. In animal models, caffeine can increase seizure susceptibility but can also protect from seizures. Effects seem dose-dependent and, influenced but the duration of intake and the developmental stage at which caffeine exposure started. Caffeine lowers the efficacy of several anti-seizure medication, especially topiramate.

Summary: It is unclear how these findings, mainly from animal studies can be translated to the clinical condition. At present, there is no evidence to advice people with epilepsy against the use or overuse of caffeine. Until clinical studies suggest otherwise, caffeine intake should be considered as a factor in achieving and maintaining seizure control in epilepsy. 
Introduction

Epilepsy is a complex paroxysmal neurological condition characterized by recurrent seizures. The condition is relatively common with a prevalence of up to $0.7 \%$ in the general population [1-3]. Caffeine is the most consumed Central Nervous System (CNS) stimulant worldwide [4]. Given its stimulative effects, it is not surprising that people with epilepsy and health providers question whether caffeine is a trigger for seizures [5]. There are currently no guidelines that unequivocally answer this question. We review current evidence on the effect of caffeine on seizures which was also covered in a recent systematic review [6]. We attempt to provide some practical advice on whether people with epilepsy should be advised to reduce their caffeine intake.

Caffeine (1,3,7-trimethylxanthine) has been found to offset fatigue and enhance vigilance, reaction speed, information processing, arousal and motor activity. The effects of caffeine are likely due to its interaction with various neurotransmitters, most importantly adenosine [7]. Adenosine is produced as a by-product of neuronal firing. [8] It promotes sleep and reduces cortical excitability through binding to the adenosine receptors [9]. As the molecular structure of caffeine is similar to adenosine, caffeine can also bind to the adenosine A1 and A2A receptors and in doing so prevents adenosine from binding, thus acting as an adenosine-antagonist. Caffeine also interacts with another important inhibitory neurotransmitter, gamma-aminobutyric acid (GABA), by modulating GABA-A receptors [10-12]. The activation of the adenosine A1-receptor inhibits dopamine, a neurotransmitter involved in focus and motivation, and release of glutamate, an important excitatory neurotransmitter. Caffeine thus increases dopamine and glutamate release and inhibits GABA, resulting in a stimulating net effect $[13,14]$.

\section{Clinical studies}

\subsection{Case reports}

Several case reports have suggested in that caffeine can trigger seizures in people with epilepsy. Seizures were either found to occur after the intake of unusually high (toxic) caffeine doses [15-22], or after prolonged periods of caffeine intake [23-27]. One case report describes a woman with several episodes of status epilepticus (SEs) occurring at weekends [27]. She regularly drank almost 2 liters of coffee on Fridays, Saturdays and Sundays, and around half a liter of coffee on weekdays. When she stopped drinking coffee at the weekends, she had fewer seizures and no episodes of SEs [27]. In another case, a man with at least six focal pharmaco-resistant seizures weekly, became seizure-free after stopping drinking more than 2 liters of coffee per day [25]. Conversely, there is a report of a man with generalized epilepsy who had been seizure-free on anti-seizure medication, but his seizures recurred when he started drinking large quantities of caffeinated iced tea [23]. The seizures decreased again when he started to drink decaffeinated iced tea. There are also anecdotal reports of seizures after the intake of energy drinks [28]. Caffeine was also found to prolong seizures after electroconvulsive therapy, a treatment for severe depression [29].

\subsection{Clinical studies on the effect of caffeine on seizures}

There are only a few clinical studies on the effect of caffeine on seizures. One was an observational study of people attending hospital after a seizure. They were asked about their usual caffeine intake [30]. On average, the coffee consumption on the day preceding the seizure was not higher than their average consumption, or than the consumption on a seizure-free day. About two thirds of them were diagnosed with epilepsy. In this subgroup, there was a trend towards less caffeine consumption prior to the seizure compared to the habitual intake, which was statistically significant in those with generalized epilepsy 
[30]. This may suggest that caffeine withdrawal plays a role in triggering seizures in some forms of epilepsy.

Two other studies were large questionnaire studies, examining the effect of prolonged caffeine intake on seizures and epilepsy. The first study assessed several health and lifestyle parameters in over 100,000 nurses, including epilepsy, seizures and caffeine intake [31]. Those reporting seizures or epilepsy did not have a different caffeine intake than the total cohort. A second study assessed whether caffeine exposure in the womb influenced the development of febrile seizures, using a questionnaire on lifestyle during pregnancy of over 35,000 women receiving antenatal care in Denmark [32]. Maternal caffeine intake during pregnancy did not influence the risk of febrile seizures in the first three months of life. This study did not provide a long-term follow-up or information on seizures other than febrile seizures. In pre-term infants, caffeine citrate can be used to improve the microstructural development of white matter. In a randomized controlled trial, infants were given either the standard dose of $30 \mathrm{mg} / \mathrm{kg}$ or a high dose of $80 \mathrm{mg} / \mathrm{kg}$ of caffeine citrate [33]. In the group receiving the high dose there was a nonsignificant trend for more numerous and longer seizures compared to children that had received the standard dose.

The anti-seizure drugs phenytoin enhanced caffeine clearance and reduced the mean half-life of caffeine was reduced by almost 50\%. Carbamazepine and valproic acid did not affect caffeine metabolism [34].

Animal studies on the effects of caffeine on seizures

Seizures after caffeine exposure

In studies with rats, mice, rabbits, guinea pigs, cats and dogs it has been found that extremely high doses of caffeine increase brain excitability and trigger seizures and encephalopathy. Caffeine is therefore used as an animal model of seizures [35]. When seizures are triggered by other agents such as pentylenetetrazol (PTZ), another animal model for epilepsy, caffeine also lowers the seizure threshold [36-39].

\section{2}

Seizures after maternal caffeine exposure

The offspring of rat dams that received caffeine during pregnancy in doses that would be equivalent to about three to four cups of coffee a day in humans were shown to be more susceptible to seizures induced by hyperthermia or flurothyl than controls that received only water [40, 41]. In the pups that had been exposed to caffeine, there was a delayed migration of GABAergic neurons into the hippocampus which was not found in controls. This delayed migration was associated with a general increase in neuronal network excitability [40]. Another study, reported no difference in adenosine A1, A2A and GABA-A receptor mRNA expression in rat pups that had been exposed to caffeine in utero compared to a control group that had not [42].

\subsection{Protective effects of caffeine}

It may come as a surprise that there are studies in animals suggesting that caffeine may have protective effects against epilepsy and seizures. In young rodents for example, prolonged, low-dose caffeine exposure was shown to decrease seizure susceptibility. One study administered caffeine to rats in the first week after birth [43]. They were also infused with one of five pro-convulsants: PTZ, picrotoxin, bicuculline, strychnine or kainic acid until the first myoclonic jerk appeared. Compared to controls, rat pups that had been exposed to caffeine had a $20-40 \%$ higher seizure threshold to PTZ at 28 days after birth. There was a further increase in seizure threshold (40-50\% elevation) to PTZ and picrotoxin in rats of 42 days old that had been given caffeine compared to controls. In adulthood (70-90 days) the caffeine group showed a significant increase of seizure threshold for PTZ and kainic acid compared to controls. 
In another study, chronic low doses of caffeine 7-11 days after birth significantly elevated the seizure threshold for generalized tonic clonic seizures (GCTS) but not for myoclonic jerks or minimal clonic seizures [44]. The seizure threshold in response to electrical stimulation was not altered in rats that received caffeine repeatedly for 7 to 11 days, or for 13 to 17 days after birth [45], nor when electrical seizures were induced at 67 days [46]. In a PTZ model of absence and myoclonic seizures, low-dose exposure to caffeine reduced the frequency of seizure-like episodes and shortened their duration in a dose-dependent fashion [47]. The anti-seizure medication phenobarbital is commonly used to treat neonatal seizures but carries the risk of inducing neurodegeneration [48]. A study was carried out to assess the neuroprotective properties of caffeine to counter the degeneration caused by phenobarbital. On day 4 after birth, the rat pups received phenobarbital with or without caffeine for three consecutive days. In the brains of rats that received phenobarbital only, there was an increase of cell death, not seen in pups which had received caffeine co-treatment. Caffeine appeared to reduce inflammatory cytokines and neurotoxicity and to counter the reduction of A1- and A2A receptors induced by phenobarbital [48]. In juvenile rats, caffeine combined with ethanol increased the vulnerability to seizures triggered with PTZ, whereas caffeine alone had a protective effect [49].

\section{Caffeine exposure in adult rodents}

Studies on the potential protective effects of caffeine against seizures and epilepsy in adult animals have shown conflicting results. One study found no effect of chronic low-dose exposure to caffeine on seizures triggered with picrotoxin or kainic acid compared to the control (water) [50]. Another study, however, found that the duration of convulsions was significantly decreased in animals receiving caffeine over several days compared to an injection with saline [51]. The differences between these two studies may be explained by methodological differences, including the different methods of caffeine administration, and use of different pro-convulsive triggers.

In a rat model of genetic absence epilepsy, the number and duration of spike-and-wave discharges (SWDs) on intracranial EEG recordings were dose-dependently reduced after a single medium dose of caffeine, compared to the baseline. This study found no effect of a more chronic exposure to caffeine [52]. A more recent study also showed a decrease in SWD's after the administration of caffeine, linked to an increase of cytokine levels (IL-6 and NFkB) in the thalamus [53]. In a rat model of severe traumatic brain injury, a single dose of caffeine also reduced the duration of epileptic bursts [54]. Interestingly it was shown that a single dose of caffeine significantly reduced the incidence of seizure-induced respiratory arrest in mice, which may be involved in sudden death in epilepsy (SUDEP) [55]. Overall, it appears that caffeine has neuroprotective effects against seizures in animal models of absence epilepsy, after early-life convulsions and traumatic brain injury. This effect depends on age, proconvulsant, seizure model, caffeine dose and administration method.

\subsection{Interactions between caffeine and anti-seizure medication in animal models}

Contrary to clinical studies, there is a relatively large number of studies on the interaction between caffeine and anti-seizure medication in animal models. In many, maximal electroshock (MES) was used to induce seizures to assess the effects of caffeine administration on the anticonvulsant properties of drugs [56-62]. Rats were injected with caffeine as well as one of following ASMs: carbamazepine, phenytoin, phenobarbital, valproic acid, felbamate, oxcarbazepine, lamotrigine, tiagabine, gabapentin and topiramate. Single-dose caffeine injections reduced the seizure threshold and increased the amount of phenobarbital, carbamazepine, phenytoin, topiramate, gabapentin, valproic acid and felbamate needed to protect $50 \%$ of the rats against electroconvulsions, whereas no changes were seen for 
oxcarbazepine, lamotrigine and tiagabine [56-58, 60-62]. When caffeine was chronically administered, the amount of phenobarbital, carbamazepine, phenytoin, topiramate, gabapentin and valproic acid needed to protect $50 \%$ of the rats against seizures was also increased, but again unaltered for oxcarbazepine, lamotrigine and tiagabine [57, 59-62]. The results of studies using other animal models of epilepsy such as PTZ or rhythmic vestibular stimulation were also in line with these findings [63]. Caffeine significantly decreased the amount of PTZ needed to induce seizures compared to saline [38]. Diazepam, however, increased the threshold to PTZ-induced seizures. When diazepam and caffeine were given together, the anticonvulsant effect of diazepam was decreased. When inducing seizures with PTZ in mice and rats treated with ethosuximide, carbamazepine, clonazepam, phenobarbital or valproic acid [39, 64] the amount of ethosuximide needed to protect 50\% of the mice [39] and the amount of carbamazepine needed to protect all the rats against seizures [64] was significantly elevated compared to the control group/condition. In mice, there were no effects for clonazepam, phenobarbital and valproic acid.

The interaction effects between caffeine and ASMs may occur on two different levels. First, as the concentrations of phenobarbital, clonazepam, phenobarbital, valproic acid, carbamazepine, gabapentin, topiramate and ethosuximide were unaffected in the presence of caffeine, caffeine may act as an antagonist of the anticonvulsant properties of these medications [39, 58, 61, 62]. The second, simpler explanation of the pharmacodynamic interaction between caffeine and ASMs is that caffeine increases seizure susceptibility, indirectly increasing the need for drugs, which makes it analogous to the interaction between any seizure precipitants.

Our quantitative analysis of previously published studies has shown that the interaction of caffeine and ASMs varies greatly between AEDs. While all ASMs seem to be affected by caffeine to some extent, topiramate has the strongest interaction with caffeine. Overall, there was no difference in the interaction with ASMs when comparing a single caffeine dose with repeated caffeine administration, except for carbamazepine, in which the interaction with caffeine was stronger when caffeine was administered chronically [6].

\subsection{Pathophysiological mechanisms potentially underlying the effect of caffeine on seizures}

What then may the pathophysiological mechanisms underlaying these different effects of caffeine on seizures? First, seizure susceptibility depends on brain excitability, which is influenced by genetics, structural anomalies, internal factors such as hormones and sleep and external factors such as diet. Genetics may influence (caffeine-related) seizure susceptibility in individuals, as suggested by a study in genetically mutated mice [65]. A more recent study suggests that caffeine can induce epigenetic changes that affect neuronal excitability, which may underlie epileptogenesis [66]. Sleep deficiency is an independent seizure trigger [67], as caffeine counters fatigue [4] and the sleep-promoting effects of adenosine [9], the effects of caffeine on seizure susceptibility may be related to its sleep-disrupting effects.

Early studies show that caffeine interferes with the processes that terminate the electrical seizure activity [68]. Results from in vitro studies show that caffeine causes an increase in intracellular $\mathrm{Ca}^{2}$ release and $\mathrm{Ca}^{2}$ influx, which is linked to increased seizure activity through elevated neuronal excitability and synchronous firing of neurons [69-71]. Similarly, caffeine may facilitate seizures by changing potassium currents leading to a less negative membrane potential [72], and by binding with the inhibitory A1-receptor subtype for endogenous extracellular adenosine [73, 74]. Recent findings suggest the involvement of the A2a-receptor for adenosine, which may explain the dose-dependent effects of 
caffeine [75]. Interestingly, adenosine has a role in seizure termination and postictal depression [76, 77] potentially also through control of free radicals [78, 79] which were shown to play a role in epileptogenesis [79, 80]. Long-term exposure to low doses of caffeine may have neuroprotective influences by changing A1- [81-83] and A2-receptor [54, 84, 85] density and sensitivity to adenosine and caffeine [81]. These effects are area- [81] and age-dependent [81-83, 86]. Caffeine-exposure in early life may have more protective effects than in adulthood, most likely because there are more changes in A-receptor density at young ages $[81-83,86]$.

\section{Discussion}

Evidence mainly from animal studies seems to show that caffeine can either increase seizure susceptibility or protect against seizures. The effect depends on the dose, administration type (a single dose or long-term exposure) and the developmental stage at which exposure to caffeine started. In animal studies, caffeine interacted with some ASMs, particularly topiramate. Single-high doses of caffeine seem more likely to trigger seizures than repeated low doses of caffeine, suggesting the development of tolerance to A1- and A2A-receptor blockade by caffeine [43, 46, 47, 52, 83, 87, 88].

Some studies show conflicting results, which may have been produced by the use of different models pertaining to different epilepsy types [40, 42, 52, 68, 88], different ways of inducing seizures $[39,58]$, different methods for caffeine administration, and different doses of caffeine or chemical proconvulsants [50-52, 68, 88]. Some sample sizes are small, limiting their reliability $[38,39]$.

Translating findings of animal studies to humans is a major challenge. There is a difference in caffeine metabolism between humans and animals. Caffeine doses used in many animal studies are much higher than the estimated equivalent average human caffeine consumption. So far, the findings from animal studies have not been replicated in clinical studies and provocative or protective effects of caffeine on seizure susceptibility have not been seen in humans [30-33]

Like animal studies, there are some limitations to previous clinical studies. Caffeine intake for example was measured as "units per day" [30-32,67]. This method has limitations as the size of units (cups) and concentration of caffeine probably differed between studies and participants. These studies also relied on self-reports, which are sensitive to recall and response biases. Selection bias may have been present in studies in which only women were included $[31,32]$. If it is true that caffeine does not significantly affect seizure susceptibility in humans, the lack of studies reporting such findings could be a result of publication bias, as negative results are notoriously hard to publish.

\section{Future research}

We highlight the scarcity of clinical data on the effects of caffeine on seizures and epilepsy. Findings from animal studies show that the relationship between seizures, AEDs and caffeine is complex. Translating these results to a human scenario is challenging, which makes it impossible to develop clear clinical recommendations regarding the consumption of caffeine in people with, or at risk of, epilepsy. Given the complex relationship between caffeine and seizures, the only reasonable recommendation that can be made to physicians who notice a change in seizure pattern, or pharmaco-resistant epilepsy, is that caffeine consumption should be included in history-taking.

To shed light on the influence of caffeine on seizures in humans, robust, prospective large-scale clinical studies will be paramount. Care will have to be taken to assess accurately caffeine intake and resulting 
plasma concentrations. For the clinical management of people with epilepsy, it will also be important to investigate whether caffeine, in doses consumed by the average person, interferes with ASMs. The finding that caffeine may have a preventative role in SUDEP is exciting, but it will have to be replicated in animal studies first, before any clinical studies can be undertaken [55].

\section{Conclusion}

While animal studies suggest that caffeine can increase seizure susceptibility, it is unclear how these findings in animal models translate to humans. In animals, chronic exposure to caffeine may protect against seizures. Caffeine can interact with several ASMs, especially topiramate. Until there are robust clinical studies available, caffeine intake should be included in history-taking in people with epilepsy and considered as a factor that may play a role in achieving and maintaining seizure control.

\section{Acknowledgments}

This work was partly done at UCLH/UCL Comprehensive Biomedical Research Centre, which receives a proportion of funding from the UK Department of Health's National Institute for Health Research Biomedical Research Centers funding scheme. JWS receives research support from the Dr. Marvin Weil Epilepsy Research Fund and from the UK Epilepsy Society.

\section{Disclosure of Conflicts of Interest}

None of the authors has any conflict of interest to disclose in relation to this work.

\section{Ethical Publication Statement}

We confirm that we have read the Journal's position on issues involved in ethical publication and affirm that this report is consistent with those guidelines. 


\section{References}

1. Forsgren L, Beghi E, Õun a., Sillanpää M (2005) The epidemiology of epilepsy in Europe - A systematic review. Eur J Neurol 12:245-253

2. MacDonald BK, Cockerell OC, Sander JW, Shorvon SD (2000) The incidence and lifetime prevalence of neurological disorders in a prospective community-based study in the UK. Brain 123:665-676

3. Sander JW (2003) The epidemiology of epilepsy revisited. [Curr Opin Neurol. 2003] - PubMed result. Curr Opin Neurol 16:165-70

4. Nehlig A (1999) Are we dependent upon coffee and caffeine? A review on human and animal data. Neurosci Biobehav Rev 23:563-576

5. Nehlig A (2016) Effects of coffee/caffeine on brain health and disease: What should i tell my patients? Pract Neurol 16:89-95

6. van Koert RR, Bauer PR, Schuitema I, Sander JW, Visser GH (2018) Caffeine and seizures: A systematic review and quantitative analysis. Epilepsy Behav. doi: 10.1016/j.yebeh.2017.11.003

7. Fredholm BB, Bättig K, Holmén J, Nehlig A, Zvartau EE (1999) Actions of Caffeine in the Brain with Special Reference to Factors That Contribute to Its Widespread Use. 51:

8. Brundege J, Dunwiddie T (1998) Metabolic regulation of endogenous adenosine release from single neurons. Neuroreport 9:3007-3011

9. Huang ZL, Urade Y HO (2011) The role of adenosine in the regulation of sleep. Curr Top Med Chem 11:1047-57

10. Roca D, Schiller G, Farb D (1988) Chronic caffeine or theophylline exposure reduces gammaaminobutyric acid/benzodiazepine receptor site interactions. Mol Pharmacol 33:481-485

11. Watanabe M, Maemura K, Kanbara K, Tamayama T, Hayasalo H (2002) GABA and GABA receptors in the central nervous system and other organs. Int Rev Cytol 213:1-47

12. Hossain S, Aoshima H, Koda H, Kiso Y (2003) Effects of coffee components on the response of GABA(A) receptors expressed in Xenopus oocytes. J Agric Food Chem 51:7568-7575

13. Borycz J1, Pereira MF, Melani A, Rodrigues RJ, Köfalvi A, Panlilio L, Pedata F, Goldberg SR, Cunha RA FS (2007) Differential glutamate-dependent and glutamate-independent adenosine A1 receptormediated modulation of dopamine release in different striatal compartments. J Neurochem 101:355-63

14. Solinas M, Ferre S, You Z, Karcz-kubicha M, Popoli P, Goldberg SR (2002) Caffeine Induces Dopamine and Glutamate Release in the Shell of the Nucleus Accumbens. 22:6321-6324

15. Banner W, Czaijka P (1980) Acute Caffeine Overdose in the Neonate.

16. Mueller SM, Solow EB (1981) Seizures Associated with a New Combination “Pick-Me-Up " Pill Inappropriate Secretion of Antidiuretic Hormone Associated with. 46202

17. Bolton V, Leicht C, Scanlon T (1989) Postpartum seizure after epidural blood patch and intravenous caffeine sodium benzoate. Anesthesiology 70:146-149

18. Cohen SM, Laurito CE, Jo Curran M (1992) Grand mal seizure in a postpartum patient following intravenous infusion of caffeine sodium benzoate to treat persistent headache. J Clin Anesth 4:48-51

19. Paech M (1996) Unexpected postpartum seizures associated with postdural puncture headache treated with caffeine.

20. Iyadurai SJP, Chung SS (2007) New-onset seizures in adults: possible association with consumption of popular energy drinks. Epilepsy Behav 10:504-8

21. Chang I, Immunogenicity KKP, Röggla G, Moser B (2007) Seizures in a night club The printed. 370:2007

22. Babu KM, Zuckerman MD, Cherkes JK, Nrcc TC, Hack JB (2011) First-Onset Seizure After Use of 5hour ENERGY. 27:539-540 
23. Kaufman K, Sachdeo R (2003) Caffeinated beverages and decreased seizure control. Seizure 12:519521

24. Antonaci F, Sances G, Manni R, Buzzi M (1996) Epileptic seizure during aspirin and caffeine withdrawal in a drug induced headache. Funct Neurol 11:333-337

25. Bonilha L, Li LM (2004) Heavy coffee drinking and epilepsy. Seizure 13:284-5

26. Maiga D, Seyni H, Sidikou A, Azouma A (2012) Convulsive crisis in Tramadol and caffeine abusers: about 8 cases and review of the literature. Pan Afr Med J. 13:

27. Mackow MJ, Krishnan B, Bingaman WE, Najm IM, Alexopoulos A V., Nair DR (2016) Increased Caffeine Intake Leads to Worsening of Electrocorticographic Epileptiform Discharges as Recorded with a Responsive Neurostimulation Device. Clin Neurophysiol 127:2341-2342

28. Borron SW, Watts SH, Herrera J, Larson J, Baeza S, Kingston RL (2018) Energy drink exposures reported to Texas poison centers: Analysis of adverse incidents in relation to total sales, 2010-2014. Regul Toxicol Pharmacol 97:1-14

29. Hinkle P, Coffey C, Weiner R, Cress M, Christison C (1997) Use of caffeine to lengthen seizures in ECT. Am J Psychiatry 144:1143-1148

30. Samsonsen C, Bråthen G, Reimers A, Helde G, Brodtkorb E (2013) Is dietary caffeine involved in seizure precipitation? Epilepsy Behav 28:147-150

31. Dworetzky B, Bromfield E, Townsend M, Kang J (2011) A prospective study of smoking, caffeine, and alcohol as risk factors for seizures or epilepsy in young adult women: Data from NUrses' Health Study II. Natl Institutes Heal 51:198-205

32. Vestergaard M, Wisborg K, Henriksen TB, Secher NJ, Ostergaard JR, Olsen J (2005) Prenatal exposure to cigarettes, alcohol, and coffee and the risk for febrile seizures. Pediatrics 116:1089-94

33. Vesoulis ZA, Mcpherson C, Neil JJ, Mathur AM, Inder TE (2016) Early High-Dose Caffeine Increases Seizure Burden in Extremely Preterm Neonates : A Preliminary Study. 6:101-107

34. Wietholtz H, Zysset T, Kreiten K, Kohl D, Bichsel R, Matern S (1989) Effect of phenytoin, carbamazepine, and valproic acid on caffeine metabolism. Eur J Clin Pharmacol 36:401-406

35. Chu N (1981) Caffeine- and Aminophylline-Induced Seizures. Epilepsia 22:85-94

36. Löscher W, Schmidt D (1988) Which animal models should be used in the search for new antiepileptic drugs? A proposal based on experimental and clinical considerations. Epilepsy Res 2:145-181

37. Cutrufo C, Bortot L, Giachetti A, Manzini S (1992) Differential effects of various xanthines on pentylenetetrazole-induced seizures in rats: an EEG and behavioural study. Eur J Pharmacol 222:1-6

38. Goto M, Morishita S, Fukuda H (1983) Anticonvulsant Action of Diazepam in Mice Pretreated with Caffeine. J Pharm Dyn 6:654-659

39. Luszczki J, Zuchora M, Sawicka K, Koziñska J, Czuczwar S (2006) Acute exposure to caffeine decreases the anticonvulsant action of ethosuximide, but not that of clonazepam, phenobarbital and valproate against pentetrazole-induced seizures in mice. 652-659

40. Silva CG, Métin C, Fazeli W, et al (2013) Adenosine receptor antagonists including caffeine alter fetal brain development in mice. Sci Transl Med 5:197ra104

41. Fazeli W, Zappettini S, Lawrence S, Grendel J, Esclapez M, Bernard C, Isbrandt D (2017) Early-life exposure to caffeine affects the construction and activity of cortical networks in mice. Exp Neurol 295:88-103

42. Adén U, Herlenius E, Tang LQ, Fredholm BB (2000) Maternal caffeine intake has minor effects on adenosine receptor ontogeny in the rat brain. Pediatr Res 48:177-183

43. Guillet R (1995) Neonatal caffeine exposure alters seizure susceptibility in rats in an age-related manner. Dev Brain Res 89:124-128

44. Tchekalarova J, Kubová H, Mareš P (2007) Effects of postnatal caffeine exposure on seizure 
susceptibility in developing rats. Brain Res 1150:32-39

45. Tchekalarova J, Kubová H, Mareš P (2010) Postnatal period of caffeine treatment and time of testing modulate the effect of acute caffeine on cortical epileptic afterdischarges in rats. Brain Res 1356:121129

46. Tchekalarova J, Kubová H, Mareš P (2013) Effects of caffeine on cortical epileptic afterdischarges in adult rats are modulated by postnatal treatment. Acta Neurol Belg 113:493-500

47. Tchekalarova J, Kubová H, Mareš P (2009) Postnatal caffeine treatment affects differently two pentylenetetrazol seizure models in rats. Seizure 18:463-469

48. Endesfelder S, Weichelt U, Schiller C, Winter K, von Haefen C, Bührer C (2018) Caffeine Protects Against Anticonvulsant-Induced Impaired Neurogenesis in the Developing Rat Brain. Neurotox Res 34:173-187

49. Matovu D, Alele PE (2018) Seizure vulnerability and anxiety responses following chronic coadministration and acute withdrawal of caffeine and ethanol in a rat model. J Basic Clin Physiol Pharmacol 29:1-10

50. Hoexter MQ, Rosa PS, Tufik S, Mello LE (2005) Consequences of prolonged caffeine administration and its withdrawal on pilocarpine- and kainate-induced seizures in rats. Epilepsia 46:1401-6

51. Souza MA, Mota BC, Gerbatin RR, Rodrigues FS, Castro M, Fighera MR, Royes LFF (2013) Antioxidant activity elicited by low dose of caffeine attenuates pentylenetetrazol-induced seizures and oxidative damage in rats. Neurochem Int 62:821-30

52. Germé K, Faure J-B, Koning E, Nehlig A (2015) Effect of caffeine and adenosine receptor ligands on the expression of spike-and-wave discharges in Genetic Absence Epilepsy Rats from Strasbourg (GAERS). Epilepsy Res 110:105-14

53. Dede F, Karadenizli S, Ozsoy OD, Eraldemir FC, Sahin D, Ates N (2019) Antagonism of adenosinergic system decrease SWD occurrence via an increment in thalamic NFkB and IL-6 in absence epilepsy. J Neuroimmunol 326:1-8

54. Lusardi TA, Lytle NK, Szybala C, Boison D (2012) Caffeine prevents acute mortality after TBI in rats without increased morbidity. Exp Neurol 234:161-168

55. Faingold CL, Randall M, Kommajosyula SP (2016) Susceptibility to seizure-induced sudden death in DBA/2 mice is altered by adenosine. Epilepsy Res 124:49-54

56. Gasior M, Swiader M, Przybyłko M, Borowicz K, Turski W, Kleinrok Z, Czuczwar J (1998) Felbamate demonstrates low propensity for interaction with methylxanthines and $\mathrm{Ca} 2 \mathrm{q}$ channel modulators against experimental seizures in mice. Eur J Pharmacol 352:207-214

57. Chrościńska-Krawczyk M, Jargiello M, Czuczwar S (2007) Influence of caffeine on the protective action of some conventional and novel antiepileptic drugs. Pharmacol Rep 59:118.Abstract

58. Czuczwar SJ, Ggsior M, Janusz W, Szczepanik B, Wlodarczyk D, Kleinrok Z (1990) Influence of Different Methylxanthines on the Anticonvulsant Action of Common Antiepileptic Drugs in Mice. 31:318-323

59. Gasior M, Borowicz K, Kleinrok Z xl;la., Czuczwar S xl;la. J (1995) Chronic caffeine and the anticonvulsant potency of antiepileptic drugs against maximal electroshock. Pharmacol Biochem Behav 54:639-644

60. Chrościńska-Krawczyk M, Ratnaraj N, Patsalos PN, Czuczwar SJ (2009) Effect of caffeine on the anticonvulsant effects of oxcarbazepine, lamotrigine and tiagabine in a mouse model of generalized tonic-clonic seizures. Pharmacol Reports 61:819-826

61. Gasior M, Borowicz K, Buszewicz G, Kleinrok Z, Czuczwar SJ (1996) Anticonvulsant activity of phenobarbital and valproate against maximal electroshock in mice during chronic treatment with caffeine and caffeine discontinuation. Epilepsia 37:262-268

62. Chrościńska-Krawczyk M, Jargiełło-Baszak M, Andres-Mach M, Łuszczki JJ, Czuczwar SJ (2016) Influence of caffeine on the protective activity of gabapentin and topiramate in a mouse model of 
generalized tonic-clonic seizures. Pharmacol Reports 68:680-685

63. Hashiguchi W, Nagatomo I, Akasaki Y, Uchida M, Tominaga M, Takigawa M (2001) Influences of caffeine to nitric oxide production and zonisamide concentration in the brain of seizure-susceptible EL mice. Psychiatry Clin Neurosci 55:319-324

64. Kulkarni C, Joseph T, David J (1989) Inhibition of anticonvulsant action of carbamazepine by aminophylline and caffeine in rats ONLY ABSTRACT. Indian J Exp Biol 27 (12):1048-51

65. Seale TW, Carney JM, Rennert OM, Flux M, Skolnick P (1987) Coincidence of seizure susceptibility to caffeine and to the benzodiazepine inverse agonist, DMCM, in SWR and CBA inbred mice. Pharmacol Biochem Behav 26:381-387

66. Williams-Karnesky RL, Sandau US, Lusardi TA, Lytle NK, Farrell JM, Pritchard EM, Kaplan DL, Boison D (2013) Epigenetic changes induced by adenosine augmentation therapy prevent epileptogenesis. J Clin Invest 123:3552-3563

67. Samsonsen C, Sand T, Bråthen G, Helde G, Brodtkorb E (2016) The impact of sleep loss on the facilitation of seizures : A prospective case-crossover study. Epilepsy Res 127:260-266

68. Albertson TE, Joy R, Stark L (1983) Caffeine Modification of Kindled Amygdaloid Seizures. Pharmacol Biochem Behav 19:339-343

69. Chen T-H, Lee B, Yang C, Hsu WH (1996) Effects of caffeine on intracellular calcium release and calcium influx in a clonal $\beta-C e l l$ line RINm5F. Life Sci 58:983-990

70. Angehagen M, Margineanu DG, Ben-Menachem E, Rönnbäck L, Hansson E, Klitgaard H (2003) Levetiracetam reduces caffeine-induced $\mathrm{Ca} 2+$ transients and epileptiform potentials in hippocampal neurons. Neuroreport 14:471-5

71. Andersen P, Bliss T, Skrede K (1971) Unit analysis of hippocampal polulation spikes. Exp Brain Res 13:208-221

72. Harinath S, Sikdar SK (2005) Inhibition of human TREK-1 channels by caffeine and theophylline. Epilepsy Res 64:127-35

73. Ault B, Olney MA, Joyner JL, Boyer CE, Notrica MA, Soroko FE, Wang CM (1987) Pro-convulsant actions of theophylline and caffeine in the hippocampus: implications for the management of temporal lobe epilepsy. Brain Res 426:93-102

74. Moraidis I, Bingmann D (1994) Epileptogenic actions of xanthines in relation to their affinities for adenosine A1 receptors in CA3 neurons of hippocampal slices (guinea pig). Brain Res 640:140-145

75. Esmaili Z, Heydari A (2019) Effect of acute caffeine administration on PTZ-induced seizure threshold in mice: Involvement of adenosine receptors and NO-cGMP signaling pathway. Epilepsy Res 149:1-8

76. Boison D (2013) Adenosine and seizure termination: endogenous mechanisms. Epilepsy Curr 13:35-37

77. Whitcomb K, Lupica CR, Rosen JB, Berman RF (1990) Adenosine involvement in postictal events in amygdala-kindled rats. Epilepsy Res 6:171-179

78. Almeida C, de Mendonça A, Cunha R a, Ribeiro J (2003) Adenosine promotes neuronal recovery from reactive oxygen species induced lesion in rat hippocampal slices. Neurosci Lett 339:127-130

79. Kovács R, Schuchmann S, Gabriel S, Kann O, Kardos J, Heinemann U (2002) Free Radical-Mediated Cell Damage After Experimental Status Epilepticus in Hippocampal Slice Cultures. J Neurophysiol 88:2909-2918

80. Gołembiowska K, Dziubina A (2012) The effect of adenosine A(2A) receptor antagonists on hydroxyl radical, dopamine, and glutamate in the striatum of rats with altered function of VMAT2. Neurotox Res 22:150-157

81. Rigoulot M-A, Leroy C, Koning E, Ferrandon A, Nehlig A (2003) Prolonged Low-dose Caffeine Exposure Protects Against Hippocampal Damage but Not Against the Occurrence of Epilepsy in the Lithium-pilocarpine Model in the Rat. Epilepsia 44:529-535 
82. Conlay L a, Conant J a, deBros F, Wurtman R (1997) Caffeine alters plasma adenosine levels. Nature 389:136

83. Johansson B, Ahlberg S (1993) Effect of long term caffeine treatment on A1 and A2 adenosine receptor binding and on mRNA levels in rat brain. Naunyn Schmiedebergs Arch Pharmacol 407-414

84. Duarte J, Agostinho P, Carvalho R, Cunha R a (2012) Caffeine Consumption Prevents Diabetes-Induced Memory Impairment and Synaptotoxicity in the Hippocampus of NONcZNO10/LTJ Mice. PLoS One 7:e21899

85. Cognato G, Agostinho P, Hockemeyer J, Müller CE, Souza D, Cunha R a (2010) Caffeine and an adenosine A2A receptor antagonist prevent memory impairment and synaptotoxicity in adult rats triggered by a convulsive episode in early life. J Neurochem 112:453-462

86. Neville HJ, Bavelier D (2000) Specificity and plasticity in neurocognitive development in humans. Director, Jefferson Headache Center, 111 South 11th St., Suite 8130, Philadelphia, PA 19107

87. Ferré S (2008) An update on the mechanisms of psychostimulant effects of caffeine. J Neurochem 105:1067-1079

88. Kostopoulos G, Veronikis DK, Efthimiou I (1987) Caffeine Blocks Absence Seizures in the Tottering Mutant Mouse. Epilepsia 28:415-420 